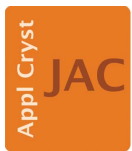

JOURNAL OF

APPLIED

CRYSTALLOGRAPHY

ISSN 1600-5767

Received 29 March 2021

Accepted 20 July 2021

Edited by S. Moggach, The University of Western Australia, Australia

Keywords: electric field crystallography; synchrotron instrumentation; proton transfer.

CCDC references: 2073116; 2073117; 2073118

Supporting information: this article has supporting information at journals.iucr.org/j
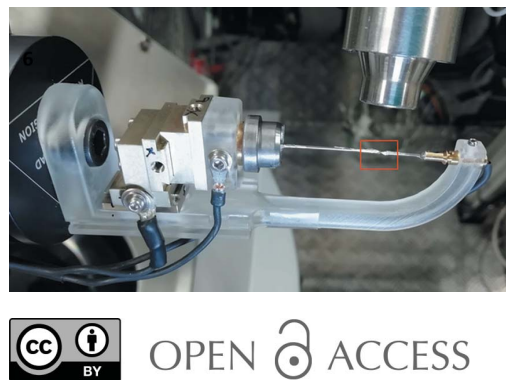

\section{An electric field cell for performing in situ single- crystal synchrotron X-ray diffraction}

\author{
Lucy K. Saunders, ${ }^{a}$ Hamish H.-M. Yeung, ${ }^{b}$ Mark R. Warren, ${ }^{a}$ Peter Smith, ${ }^{c}$ Stuart \\ Gurney, ${ }^{a}$ Stephen F. Dodsworth, ${ }^{\mathrm{a}, \mathrm{d}}$ Inigo J. Vitorica-Yrezabal, ${ }^{\mathrm{e}}$ Adrian Wilcox, ${ }^{\mathrm{a}}$ \\ Paul V. Hathaway, ${ }^{f}$ Geoff Preece, ${ }^{\mathrm{c}}$ Paul Roberts, ${ }^{\mathrm{c}}$ Sarah A. Barnett ${ }^{\mathrm{a}}$ and David R. \\ Allan ${ }^{\mathrm{a} *}$
}

\begin{abstract}
aPhysical Science, Diamond Light Source, Harwell Science and Innovation Campus, Didcot, Oxfordshire OX11 ODE, United Kingdom, ${ }^{\mathbf{b}}$ School of Chemistry, The University of Birmingham, Haworth Building, Edgbaston, Birmingham B15 $2 \mathrm{TT}$, United Kingdom, ${ }^{\mathbf{c}}$ Technical, Diamond Light Source, Harwell Science and Innovation Campus, Didcot, Oxfordshire OX11 0DE, United Kingdom, ${ }^{\mathbf{d}}$ Department of Chemistry, The University of Sheffield, Brook Hill, Sheffield S3 7HF, United Kingdom, 'Department of Chemistry and Photon Science Institute, The University of Manchester, Oxford Road, Manchester M13 9PL, United Kingdom, and 'Life Science, Diamond Light Source, Harwell Science and Innovation Campus, Didcot, Oxfordshire OX11 0DE, United Kingdom. *Correspondence e-mail: david.allan@diamond.ac.uk
\end{abstract}

With the recent increase in research into ferroelectric, anti-ferroelectric and piezoelectric materials, studying the solid-state properties in situ under applied electric fields is vital in understanding the underlying processes. Where this behaviour is the result of atomic displacements, crystallographic insight has an important role. This work presents a sample environment designed to apply an electric field to single-crystal samples in situ on the small-molecule single-crystal diffraction beamline I19, Diamond Light Source (UK). The configuration and operation of the cell is described as well as its application to studies of a protontransfer colour-change material.

\section{Introduction}

Solid-state materials can exhibit interesting dielectric phenomena on the application of an electric field. The range of behaviours includes ferroelectricity, where a spontaneous and switchable polarization is exhibited in (typically) polar systems under an electric field (Horiuchi et al., 2012); antiferroelectricity, where symmetry-opposed polar sub-units present in a material may be aligned on application of an electric field and can be coupled with a crystallographic phase transition (Tolédano \& Guennou, 2016); piezoelectricity, where the system shows a mechanical response to the field with change in, for example, the lattice/structural parameters (Werling et al., 2013); proton-transfer behaviour (Rode et al., 2016; Horiuchi et al., 2008); and the enhancement of nonlinear optical properties (Bai et al., 2013). A range of materials exist that exhibit electric field responses in the solid state, including metal oxides, metal-organic frameworks (Zhang \& Xiong, 2012), hydrogen-bonded organic molecular crystals (Stroppa et al., 2011; Horiuchi \& Tokura, 2008; Owczarek et al., 2016; Horiuchi et al., 2020) and ionic solids (Li et al., 2015; Schmalzried \& Smolin, 1998; Zhang et al., 2018; Rodzevich et al., 2017). Related to their dielectric properties, these materials can have applications as pressure sensors (Haertling, 1999), actuators (Wersing et al., 2008), memory devices (Amanuma et al., 2000, Dawber et al., 2005) and capacitors (Bouregba et al., 2003).

The electric-field-induced properties of materials are typically determined by measuring dielectric constants (Horiuchi et al., 2005) or polarization-electric field loops (Horiuchi et al., 
2013), whilst structural effects under applied electric fields are elucidated computationally (Li et al., 2015) or using techniques such as small-angle neutron scattering (Grigoriev et al., 2006). In situ diffraction measurements under an applied electric field provide a more complete understanding of the field-induced processes/mechanisms taking place at the structural level (Gorfman et al., 2013; Usher et al., 2015; Esteves et al., 2015). Electric-field-induced shifts in Bragg peak position provide information about piezoelectric strain (Gorfman et al., 2013; Hinterstein et al., 2011). Using the whole (powder) diffraction pattern can give insight into the strain mechanism (Hinterstein et al., 2015), as well as providing the possibility to investigate the response of coexisting phases (Hinterstein et al., 2019). Electric-field-induced bond distortions (Gorfman et al., 2013) or polarity switching (Kobayashi et al., 2018) may be determined by observing the relative displacement of atoms in the crystal structure or indicated by changes in diffracted intensity (Varela et al., 2000).

Several sample environments exist that allow the application of electric fields during an in situ diffraction experiment in house or at a central facility. These are optimized for both single-crystal and microcrystalline powders with a range of configurations. Single crystals usually have dimensions on the $1-10 \mathrm{~mm}$ scale and are mounted either between electrode needles (Vergentev et al., 2015, 2016; Choe et al., 2017) or on a sample holder with electrodes attached (Dos Santos et al., 2012; van Reeuwijk et al., 2000; Marchenkov et al., 2018). The latter is also frequently used for powder samples, which are usually in the form of pellets. Full crystal structure determination under applied electric fields is still relatively uncommon and is less often the focus of a measurement; fieldinduced structural shifts or distortions tend to be very small, requiring the diffraction intensities instead to be probed.

In this contribution, we present a new sample environment on beamline I19-2, Diamond Light Source (Nowell et al., 2012), which allows full structure determination from singlecrystal samples under an applied electric field. Acknowledging the existing setups, here we aim to extend the in situ capabilities of the I19-2 beamline to electric field measurements and to better suit the small-molecule chemical crystallography user community, whose samples are typically of the order of less than $1 \mathrm{~mm}$. The I19 electric field (ELF) sample cell permits the application of static/alternating fields (DC/ AC) up to $4 \mathrm{kV}$ with an opening angle to X-rays of $c a 250^{\circ}$. We present the design elements and include a case study to show its potential for in situ measurements. This new sample environment makes advances in the application of electric fields to those samples on the sub-millimetre scale, whilst offering the opportunity to study processes on microsecond timescales when combined with the I19-2 time-resolved mode.

\section{In situ electric field application on I19-2}

The schematic in Fig. 1 shows the hardware configuration for applying an electric field to a sample in situ during an X-ray diffraction experiment on beamline I19-2 at Diamond Light Source, UK. The basic electrical connections are based on a
Sawyer-Tower circuit (Sawyer \& Tower, 1930). The sample is connected in series to a voltage supply (generating the electric field), with the capability to measure the sample response to electric field via a reference capacitor. The generation of the electric field starts at a function/arbitrary waveform generator (AGILENT 33210A $10 \mathrm{MHz}$ ). This device allows the characteristics of the electric field at the sample to be controlled and varied. The user selects the function (pulse, sinewave, ramp etc.), frequency (Hz) and amplitude (volts) of an initial low-voltage signal. Once programmed, this signal is output to the high-voltage amplifier (TREK model 610E) via a bayonet Neill-Concelman (BNC) double-ended cable to the amplifier's external signal input connector (AMP INPUT Receptacle). The amplifier steps up the low-voltage signal to a 1000-fold-amplified high-voltage output.

The high-voltage output is supplied to the sample via an intermediate capacitor bank, designed in house (Fig. 1: I19CAPBOX). The I19-CAPBOX is designed to include both safety and control features. The safety features prevent user access to the I19 ELF cell during voltage loading. This is achieved by the I19-CAPBOX forming an intermediate connection between the experiment hutch interlock, the highvoltage amplifier and the I19 ELF cell. The I19-CAPBOX receives a relay signal from the hutch interlock and only enables the high-voltage amplifier via the external control input when the hutch is in an interlocked state. The same principle is used for receiving X-rays from the synchrotron. The I19-CAPBOX also provides electrical protection to the system through a surge protector which prevents very high voltages from reaching delicate components in the circuit, such as the electrometer. It also incorporates a selection of reference capacitors in a Sawyer-Tower circuit configuration, with which polarization loops of ferroelectric materials may be recorded simultaneously (XMaS; https://warwick.ac.uk/fac/cross_ fac/xmas/xmas_offline/electrical_measurements). This reference

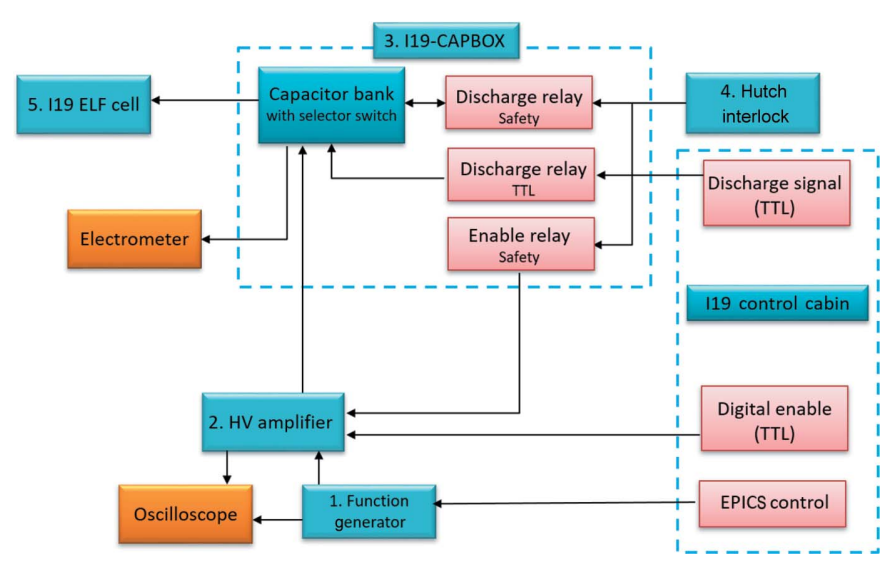

Figure 1

Schematic of the I19 ELF hardware on the I19-2 beamline, including (2) a high-voltage (HV) amplifier and (3) an intermediate capacitor bank (I19CAPBOX). Connections (arrows) and control signals [TTL: transistortransistor logic signal; EPICS: Experimental Physics and Industrial Control System (http://www.aps.anl.gov/epics/)] are also shown. Colour scheme: operating components (blue), monitoring devices (orange), signals (red). 
capacitor is automatically reset following a voltage-loading experiment on breaking the hutch interlock, as a further safety control (ensuring there are no charged components remaining during sample-cell exchange). The I19-CAPBOX has highvoltage output and grounding connectors to which high-voltage cabling can be connected for the attachment of the sample cell during voltage loading. In the current configuration, voltages up to $4000 \mathrm{~V}$ can be generated for use in an experiment.

\subsection{I19 electric field cell}

2.1.1. Sample holder. The I19 ELF cell is based on a previous design by Vergentev et al. (2015) in which a single crystal is mounted between two collinear electrodes which are held in place by a mounting bracket. For the I19 ELF cell (Fig. 2), the mounting bracket is streamlined (dimensions $95 \times 30 \times 15 \mathrm{~mm}$ ) to optimize the accessible region of reciprocal space (the opening angle to diffraction at kappa $0^{\circ}$ is $250^{\circ}$ of a $\varphi / \omega$ scan). This has been achieved by using $3 \mathrm{D}$ printing, allowing the mounting bracket design to be quickly and cheaply optimized. The bracket is 3D printed from FormLabs resin plastic, which retains a rigid structure to maintain sample centring. As the cell bracket passes through the X-ray beam it causes some shading of the diffraction images (see Section 2.3). This shading is low owing to the use of the resin plastic material and is kept consistent across measurements by mounting the sample cell on the diffractometer always in the same orientation and using a level bar to maintain the same position within tolerances of human error. This mounting method also ensures that the cell is in its expected position for the start of the data collection to provide safe movement through the data collection run list.

2.1.2. Electrical connections. One sample electrode is detachable from the magnetic goniometer base, allowing crystal mounting offline, and sits in the cell on an Elliot Scientific/Martock MDE269 three-axis ultra-small xyz micropositioner stage to facilitate alignment and crystal docking to the second electrode, which is held in position by a brass pin. The I19 ELF cell is connected to the I19-CAPBOX via highvoltage cabling fed through and secured in the I19-2 diffractometer. Voltage is delivered to the sample through the use of a junction box, which forms the connection between the high-voltage cabling from the I19-CAPBOX and the slimline wiring connected to the sample electrodes on the I19 ELF cell. The sample cell with junction box attachment is mounted onto the I19-2 diffractometer on a metal stand support (Fig. 3) with kinematic magnets for ease of mounting.

2.1.3. Electrode preparation. The electrodes are two industry-standard pin loops, such as the Mitegen MicroMount/
Loop, which are pre-coated at the tip in conductive paint such as Electrolube Silver Conductive Adhesive paint (Fig. 4). The sample pin electrodes are glued into either the goniometer base or brass holder. Electrical connections are then ensured between the electrode and the holder by connecting lines of silver paint. This setup also allows for alternative electrodes to be used, such as graphite fibres or steel pins, which may be

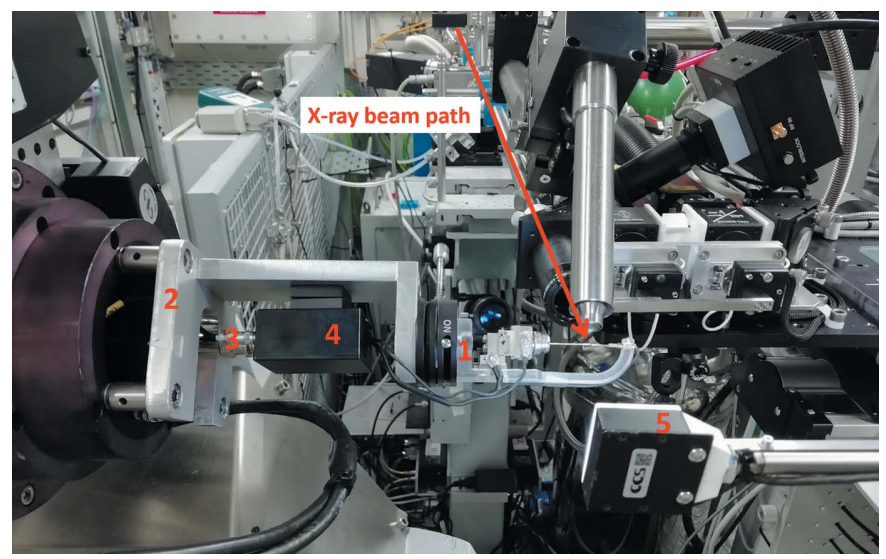

Figure 3

I19 ELF cell in operation. (1) The cell mounted in position on the I19-2 diffractometer, (2) the metal stand attached to the diffractometer, (3) cables from the I19-CAPBOX (fed through and secured in place in the I19-2 diffractometer), (4) the junction box, which connects the slim cell wiring with the high-voltage input and ground cables, and (5) a backlight, which moves into position for crystal illumination during sample centring. The X-ray beam path is highlighted (red arrow). The Pilatus 300K X-ray detector is not in position in the image but, during a diffraction experiment, is moved into position 5 for data collection and the backlight is moved out. 


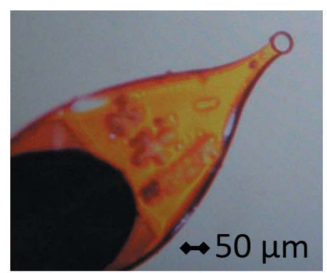

(a)

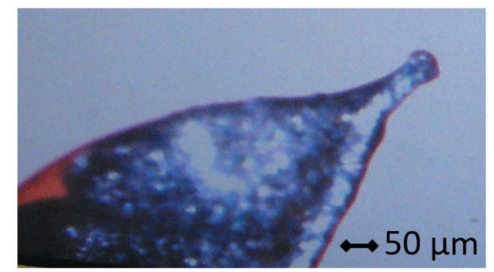

(b)
Figure 4

Sample pin electrode preparation before $(a)$ and after $(b)$ using silver paint to coat a MicroMount/Loop.

attached to the silver-coated loops or inserted directly into the base or brass holder, using a conductive adhesive.

2.1.4. Sample preparation. Single crystals selected for mounting in the I19 ELF cell should be manipulated dry or in the mother liquor before electrode attachment. This ensures optimum connections between the crystal and electrodes both in terms of securing in place (during gluing) and for electric field transfer. Currently the cell is optimized for crystals of at least $100 \mu \mathrm{m}$ in all directions. There is no maximum limit in sample size, but those significantly larger than the beam size $(190 \times 130 \mu \mathrm{m})$ will cause problems with absorption effects on the diffracted intensities, introducing systematic error in their measurement. For mounting, the detachable electrode 1 tip is dipped into a mixture of silver paint and epoxy (conductive adhesive) and touched against the crystal to form the first contact. The conductive adhesive mixture is preferred for secure mounting as using silver paint alone increases the likelihood of broken contacts owing to ELF cell movement during handling. This conductive adhesive mixture is left to dry (5-10 $\mathrm{min}$ ) before the detachable electrode is mounted in the cell. Using a microscope, the tip of electrode 2 is painted with the conductive adhesive, against which the crystal is then docked using the Elliot Scientific/Martock MDE269 micropositioner stage, adjusted using a hex key. This conductive adhesive mixture is again left to dry (5-10 min). Additional contacts between the electrode and crystal can be formed by the further addition of silver paint. One drawback of this choice of conductive adhesive is that the silver component generates powder rings in the diffraction pattern (see Section 2.3). Once the crystal-electrode contacts are dry, the I19 ELF cell is mounted onto the diffractometer using the kinematic magnet mount. Crystal centring is then performed using the in-house general data acquisition (GDA) software (Gibbons et al., 2012).

2.1.5. Crystal orientation. The response of a crystalline material to an electric field is most often dependent on the orientation of the applied electric field with respect to the crystal lattice (Horiuchi \& Ishibashi, 2020; Tazaki et al., 2009; Owczarek et al., 2016). A crystal should therefore be mounted in the cell in such an orientation that the axis of interest coincides with the direction of the applied electric field. It is recommended to perform face indexing on crystals for use in the I19 ELF cell to obtain knowledge of crystal morphology versus crystal lattice/structure orientation. This can be carried out prior to beamtime on an in-house instrument or during the beamtime on I19-2 by performing a single $\varphi$ scan on a crystal perpendicular to the X-ray beam. At I19-2, this rotation scan is performed twice, once to collect diffraction images and a second time to collect on-axis camera images. Indexing is performed from the diffraction images and the indexed reciprocal lattice vectors are overlaid onto the diffraction images in the DIALS (Diffraction Integration for Advanced Light Sources; Winter et al., 2018) image-viewer software. By comparing the rotation of the reciprocal lattice vectors with the corresponding crystal rotation in the camera images (Fig. 5), the crystal morphology can be compared with the crystal structure. The tool BFDH (Bravais, Friedel, Donnay and Harker) in Mercury (Macrae et al., 2006, 2020) can also be a useful alternative, relating crystal structure to calculated morphology.

\subsection{User controls and monitoring}

Once the I19 ELF cell is mounted on the diffractometer, the full experiment can be controlled remotely from the I19 control cabin. Control of the voltage applied to the sample is achieved by operation of the high-voltage amplifier in

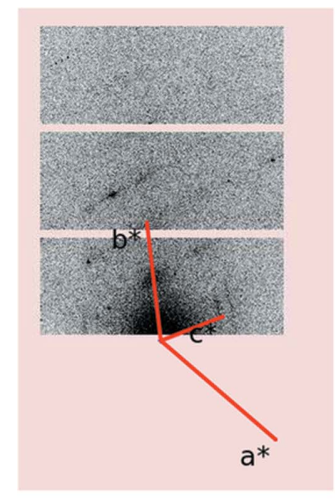

(a)

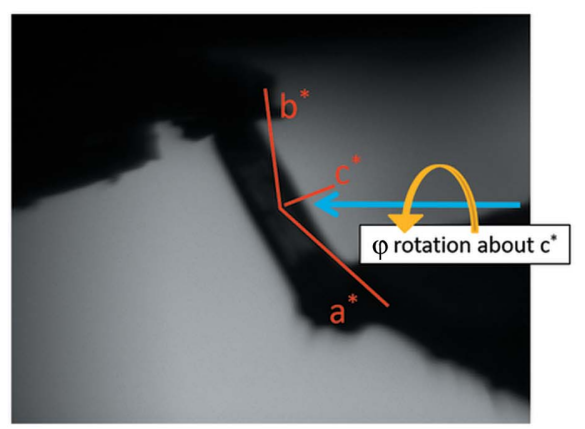

(b)

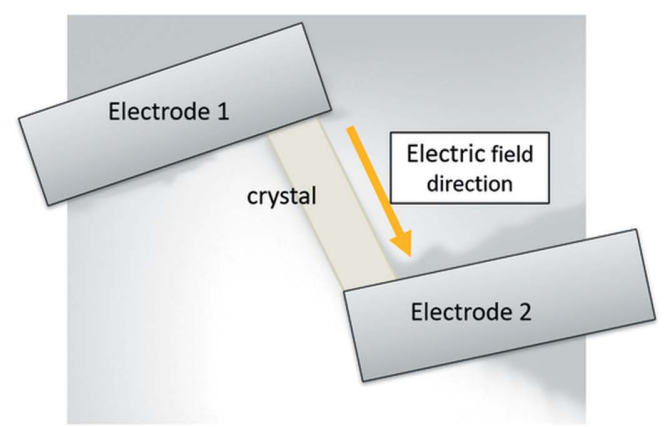

(c)

Figure 5

(a) Relationship between reciprocal lattice vectors in a diffraction image viewed in the DIALS image viewer, and (b) the corresponding crystal orientation between electrodes in the electric field cell, viewed using the on-axis viewing camera. $(c)$ The equivalent schematic with electrodes, crystal and electric field direction labelled. This information can be used as a guide to indicate which crystallographic axis the electric field is being applied along and which axis, or combination of axes, electric-field-induced changes are likely to be observed in (Tazaki et al., 2009). 
'Remote' mode and using on/off TTL (transistor-transistor logic) signals sent via scripts incorporated into the GDA software. The reference capacitor can also be discharged on demand using a TTL signal sent via a script in the GDA software, allowing the system to be reset for further voltage loading or sample exchange. The voltage to be amplified is programmed in the arbitrary waveform function generator using an Experimental Physics and Industrial Control System (EPICS; http://www.aps.anl.gov/epics/) interface built with Extensible Display Manager (EDM; Sinclair, 2007). The programmed output from the function generator is then monitored using an oscilloscope. Oscilloscopes are further used to monitor the high-voltage amplifier outputs of the voltage $\left(V_{0}\right)$ and current $\left(I_{0}\right)$, stepped down 1000 -fold. The amplifier also has a meter display on the front panel showing the amplified voltage output. The two oscilloscopes and amplifier meter panel can be monitored from the control cabin using one of the beamline webcams located inside the hutch. The hardware configuration has the capability to measure the sample response to electric field via the incorporation of an electrometer (Fig. 1) with the possibility of remote monitoring through the GDA software and the EPICS interface built with $E D M$. This capability is a necessity in extending the setup to time-resolved measurements and correlating structural changes with changes in the electronic response of the sample.

\subsection{Data collection and processing}

X-ray diffraction data collection from samples in the I19 ELF cell is performed using the GDA software. Diffraction data are collected with the electric field initially off for a 'ground state experiment' and then with the electric field on for any electric-field-induced structural changes to be observed. The sample temperature can additionally be varied between 80 and $500 \mathrm{~K}$ using an Oxford Cryosystems Cryostream, which is carefully positioned so that its nitrogen gas flow is optimally directed at the sample. At lower operating temperatures $(<200 \mathrm{~K})$, significant icing of the sample electrodes occurs when in the flow of the Cryostream for prolonged periods of time. This can lead to sample loss or degradation. This is unavoidable owing to the orientation of the sample electrodes relative to the flow of the liquid nitrogen from the Cryostream nozzle. To mitigate against ice buildup, the ice can be cleared periodically by careful dislodging or by brief blocking of the Cryostream flow. An alternative contact cooling system (Mykhaylyk et al., 2017) would be preferable but has not yet been incorporated into the current phase of the cell.

Data collections are run at the relatively high energy $\mathrm{Rh}$ edge $(0.534 \AA)$, selected to compress the diffraction pattern and to keep the number of $2 \theta$ detector positions to a minimum, whilst operating at an energy away from the $\mathrm{Ag}$ edge which would interact with the silver paint conductive adhesive used. At a single position of $2 \theta=28^{\circ}$ and detector distance $=100 \mathrm{~mm}$, a diffraction resolution of $0.6 \AA$ can be achieved. The I19-2 Newport four-circle diffractometer allows a data collection strategy to be performed that includes three $\varphi$ scans (over a -176 to $108^{\circ}$ range) at fixed $\omega\left(-33^{\circ}\right)$ and varying $\kappa\left(0,-42,60^{\circ}\right)$ and two $\omega$ scans at varying $\varphi(-120$, $\left.-5^{\circ}\right)$ and fixed kappa $\left(60^{\circ}\right)$ positions.

Because of the way that the I19 ELF cell is designed, powder rings from the silver conductive adhesive and shading from the cell bracket occur on a proportion of the diffraction images [Figs. 6(a) and 6(b)]. This leads to a reduction in diffraction intensity in the affected images. Despite this, it is possible to collect diffraction data from monoclinic or highersymmetry systems with a good coverage of reciprocal space [Figs. 6(c)-6(e) and Fig. S1 in the supporting information]. The powder rings and shading from the I19 ELF cell in the diffraction images can be accounted for in the data processing, which is performed using xia2 (Winter, 2010) with DIALS (Winter et al., 2018). For weakly diffracting samples, it is recommended to use a combination of masking and the removal of sections of the shaded data during the data processing. This can result in a reduced completeness of the diffraction data but improved merging statistics. For strongly diffracting samples with a low mosaic spread, good data processing statistics can be achieved using the default xia2/ $D I A L S$ settings on all of the diffraction data (Table 1). DIALS treats the affected data initially during the spot finding, where affected intensities are either undetected or rejected on the

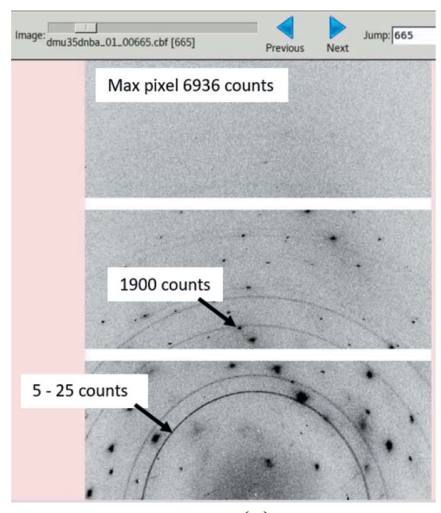

(a)

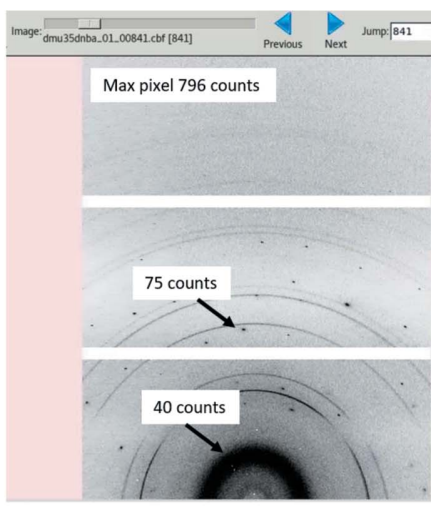

(b)

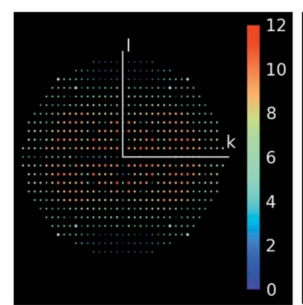

(c)

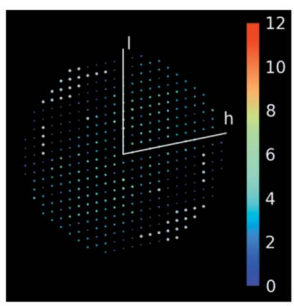

(d)

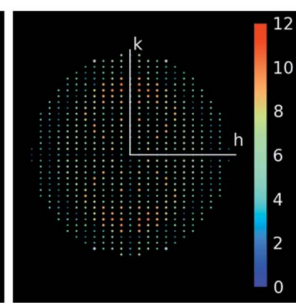

(e)
Figure 6

Diffraction images from a single crystal mounted in the $\mathrm{I} 19$ electric field cell $\left(\lambda 0.534 \AA\right.$ and $\left.2 \theta 28^{\circ}\right)$. (a) An image free of shading from the cell and (b) an image shaded by the cell mounting bracket, showing how the observed diffraction is weaker. The images contain diffraction spots from the sample and powder rings from the silver component of the conductive paste. $(c)-(e) h k l$ plots showing the distribution of reflection multiplicities in reciprocal space $(d=0.67 \AA)$ for data collection and reduction of a data set collected from the monoclinic $\left(P 2_{1}\right)$ system $N, N$-dimethylurea 3,5dinitrobenzoic acid (Saunders et al., 2019) at $300 \mathrm{~K}$. Reflections are coloured according to their multiplicity $(0-12$; see bar on the right of each image). 
Table 1

Statistics following data reduction in xia2 of an I19 ELF cell data set collected from the monoclinic $\left(P 2_{1}\right)$ system $N, N$-dimethylurea 3,5dinitrobenzoic acid (Saunders et al., 2019) at $300 \mathrm{~K}$.

Additional data processing commands used include a resolution cut-off of $0.67 \AA$; full processing details are included in Tables S1 and S2 in the supporting information.

\begin{tabular}{llll}
\hline & Overall & Low resolution & High resolution \\
\hline Resolution $(\AA)$ & $11.48-0.67$ & $11.48-1.81$ & $0.68-0.67$ \\
Observations & 11755 & 887 & 415 \\
Unique reflections & 2424 & 139 & 117 \\
Multiplicity & 4.8 & 6.4 & 3.5 \\
Completeness $(\%)$ & 97.51 & 100.00 & 94.35 \\
Mean $I / \sigma(I)$ & 25.8 & 197.4 & 1.0 \\
$R_{\text {merge }}$ & 0.025 & 0.009 & 0.360 \\
\hline
\end{tabular}

basis of a maximum peak-to-centroid separation (in pixels) criterion. Later, in the DIALS scaling routine, any affected intensities are subject to further rejection if they deviate significantly from the expected Wilson distribution (Wilson, 1942; Giacovazzo et al., 2011).

\section{Case study: electric-field-induced colour change in} single crystals of $4,4^{\prime}$-bipyridinium hydrogen squarate

The crystallization of squaric acid with 4,4'-bipyridine generates a 1:1 adduct where, at room temperature, the acid and bipyridine molecules are present in their monoprotonated forms in space group $P 2_{1} / n$ (SQABPY-I). Single crystals of SQABPY-I are in the form of rectangular needles and are yellow ochre in colour (Reetz et al., 1994). This system has previously been shown to exhibit temperature- and pressureinduced proton-transfer behaviour by single-crystal X-ray

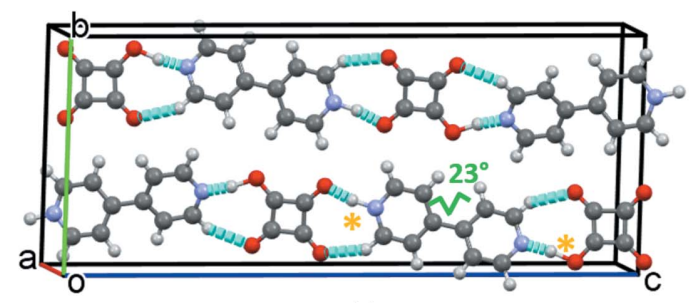

(a)

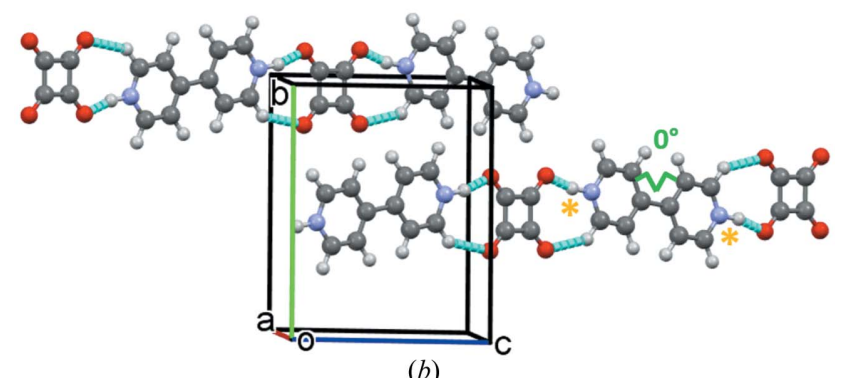

Figure 7

Hydrogen-bonded chains in the crystal structures of (a) SQABPY-I $\left[P 2_{1} / n\right.$ form; Cambridge Structural Database (CSD) refcode HAZFAP01; Martins et al., 2009] and (b) SQABPY-II (C2/c form; CSD refcode HAZFAP07; Martins et al., 2009), showing the differing protonation states (orange asterisks) and molecular torsions of bipyridine rings (green lines). Hydrogen bonds are drawn as dashed cyan lines. diffraction, neutron powder diffraction, and optical and infrared spectroscopy (Martins et al., 2009). The protontransfer event occurs along hydrogen-bonded chains in the crystal structure from the monoprotonated squarate to the monoprotonated bipyridinium to form a diprotonated bipyridinium ion (Fig. 7) and is reversible. The proton transfer is coupled with a crystallographic phase transition from space group $P 2_{1} / n$ (SQABPY-I) to $C 2 / c$ (SQABPY-II) and significant changes in lattice parameters [from $P 2_{1} / n, a=3.8000$ (10), $b=11.2080$ (10), $c=27.447$ (2) $\AA, \beta=92.220(10)^{\circ}$ to $C 2 / c, a=$ $12.465(25), \quad b=11.2747$ (11), $\quad c=9.0706(20) \AA, \quad \beta=$ $\left.109.497(13)^{\circ}\right]$. An associated colour change occurs during the phase transition, where the yellow SQABPY-I crystals turn to red in the SQABPY-II phase. This is thought to be caused by a narrowing of the squarate-bipyridinium charge-transfer energy gap following the proton transfer. The powder X-ray diffraction and differential scanning calorimetry measurements conducted by Martins et al. (2009), as well as confirming the reversibility of the phase transition, suggest a significant kinetic barrier for the conversion from SQABPY-II back to SQABPY-I; a hysteresis occurs on cooling below the phasetransition temperature, whilst subsequent cooling-heating cycles reveal a reduction in the energy change for the transition from 5.4 to $4.2 \mathrm{~kJ} \mathrm{~mol}^{-1}$.

The susceptibility of SQABPY-I to external stimuli makes it a good candidate for electric field studies in the I19 ELF cell. Proton-transfer behaviour is also known to occur under applied electric fields in ferroelectric materials, in which proton shuttling may facilitate the reversal of material polarity (Horiuchi et al., 2010, 2017; Abronin et al., 2016) or lead to transitions between electric states, including paraferro- (Yao et al., 2016; Horiuchi et al., 2005) or antiferro-ferroelectric (Horiuchi, Tsutsumi, et al., 2018). Extended hydrogen-bonded chains of acid-base molecules (such as formed in SQABPY-I) can further favour proton shuttling under an applied electric field (Horiuchi et al., 2009; Horiuchi \& Ishibashi, 2020), whilst squaric acid is found in single-component (Horiuchi, Kumai \& Ishibashi, 2018) and multi-component proton-transfer materials with multiple electric states (Lengyel et al., 2019). Materials such as these offer interesting applications, including in optical communications (Miyamoto et al., 2018) and high-power energy-storage systems (Horiuchi, Kumai \& Ishibashi, 2018) and for electrostriction applications (Kobayashi et al., 2018).

\subsection{Experimental}

Single crystals of SQABPY-I were prepared by dissolving equimolar quantities of squaric acid and 4,4'-bipyridine in $\mathrm{H}_{2} \mathrm{O}$ heated to $60^{\circ} \mathrm{C}$ and stirring continuously. Initially, a bright-orange precipitate formed as the squaric acid immediately (singly) protonates the bipyridine. This precipitate dissolved after approximately one hour of continuous heating and stirring (combining $2.5 \mathrm{mmol}$ of each component gives a reacted product that dissolves in $\sim 50 \mathrm{ml}$ of $\mathrm{H}_{2} \mathrm{O}$ at $60^{\circ} \mathrm{C}$ ). Slow cooling of the solution and evaporation (approximately two months) produces a number of large rectangular planks. A large volume of small needles can be grown by crash cooling 
(minutes to hours) of a concentrated hot aqueous solution ( $2.5 \mathrm{mmol}$ of each component in $20 \mathrm{ml}$ of $\mathrm{H}_{2} \mathrm{O}$ at $90^{\circ} \mathrm{C}$ ).

Single-crystal X-ray diffraction data were collected on crystals of SQABPY-I in the I19 ELF cell on beamline I19-2 at Diamond Light Source, UK, using a Newport four-circle diffractometer equipped with a PILATUS 300K detector and an energy of $\lambda=0.534 \AA$. Diffraction data were measured from the sample at room temperature. Data collection was performed using the in-house GDA software, and data were processed using xia2 for small molecules with additional $D I A L S$ commands to input the unit cell and space group and a resolution cut-off of $0.75 \AA$ (see Table S3). Structures were solved using SHELXT (Sheldrick, 2015a) and refined using SHELXL (Sheldrick, 2015b) in OLEX2-1.3 (Dolomanov et al., 2009). H-atom refinement details are included in the supporting information (Table S4).

Face indexing of the crystals was carried out using a Rigaku Oxford Diffraction (formerly Agilent Technologies) Supernova diffractometer with $\operatorname{Mo} K \alpha \quad(0.71073 \AA)$ radiation, equipped with an optical camera to select the crystal faces. The CrysAlisPro (1.171.40.84a; Rigaku Oxford Diffraction) software was used to index the crystal faces. Mercury was used to calculate the BFDH morphology and to determine the molecular arrangement relative to the crystal faces and unit-cell axes.

\subsection{Crystal habit}

Crystals of SQABPY-I grow as rectangular small needles or large planks (depending on the crystallization method) and always with a long length, a narrow edge and a dominant large face, corresponding to crystal width. To relate crystal structure to crystal habit, face indexing was performed on several crystals of SQABPY-I.

The faces of the SQABPY-I needles are identified as (100), (010) and (001) in all measured samples (Fig. 8 and Fig. S2). The long needle length corresponds to the crystallographic $a$ axis, capped by the (100) and (100) faces. The narrow crystal edges correspond to the (010) and (010) faces and are perpendicular to the crystallographic $b$ axis. The dominant crystal width corresponds to the (001) and (001) faces which are perpendicular to the crystallographic $c$ axis. The BFDH Mercury crystal morphology correctly predicts the $a$ axis to be the longest length of the crystal and the $c$ axis to be perpendicular to the crystal width (Fig. S3). This tool therefore has potential for the correct assignment of unit-cell orientation relative to crystal faces where an extreme axis is present.

\subsection{Offline electric field application}

Offline optical measurements were first made to test the response of the SQABPY-I crystals to the electric field and to determine if a voltage-induced colour change could be observed. A

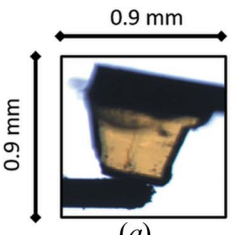

(a)
Figure 9

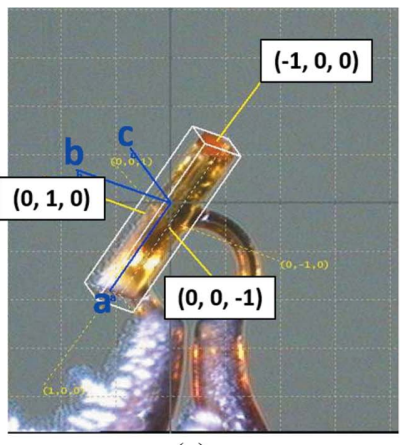

(a)

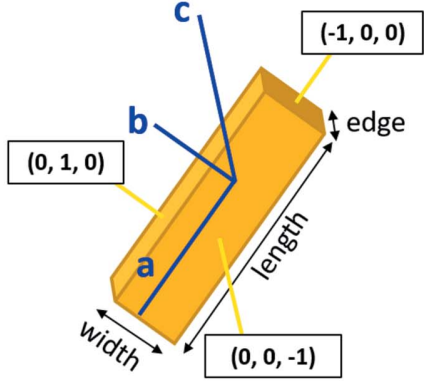

(b)
Figure 8

A face-indexed crystal of SQABPY-I: $(a)$ a small needle grown by fast cooling and (b) a pictogram depiction. Miller indices (yellow lines) of each crystal face (defined by the white box) alongside the orientation of unit-cell axes (blue lines) relative to crystal faces are shown. Face indexing was performed within the CrysAlisPro software (1.171.40.84a) using the face-indexing tool.

single crystal [dimensions: $0.60(1) \times 0.60(1) \times 0.20(1) \mathrm{mm}$ ] cut from a needle of SQABPY-I was mounted in the I19 ELF cell following the procedure outlined in Section 2.1. The SQABPY-I crystal habit favoured their mounting in the I19 ELF cell with electrodes attached to the (010) and (010) faces such that the electric field was applied parallel to the crystallographic $b$ axis.

Once the crystal had been mounted, voltage ramping was performed at room temperature and the crystal was monitored for changes using the on-axis viewing camera (Fig. 9). The voltage was increased stepwise (200 V steps) from 0 to $1800 \mathrm{~V}$. The crystal remained in its yellow form up to $1800 \mathrm{~V}$. At $1900 \mathrm{~V}\left(\simeq 3000 \mathrm{~V} \mathrm{~mm}^{-1}\right.$ ) [Fig. 9(c)], the crystal appeared to shorten parallel to the direction of field application, with an accompanying subtle colour change from yellow to a redshifted yellow. This colour change was reversible as the voltage supply to the crystal was turned off and on [Figs. $9(d)-9(f)$ ]. No further colour change was observed on increasing the

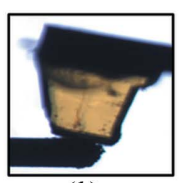

(b)

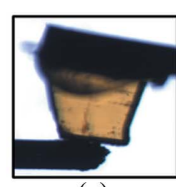

(c)

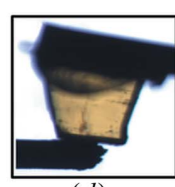

(d)

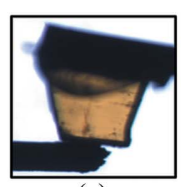

(e)

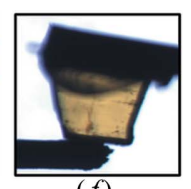

$(f)$

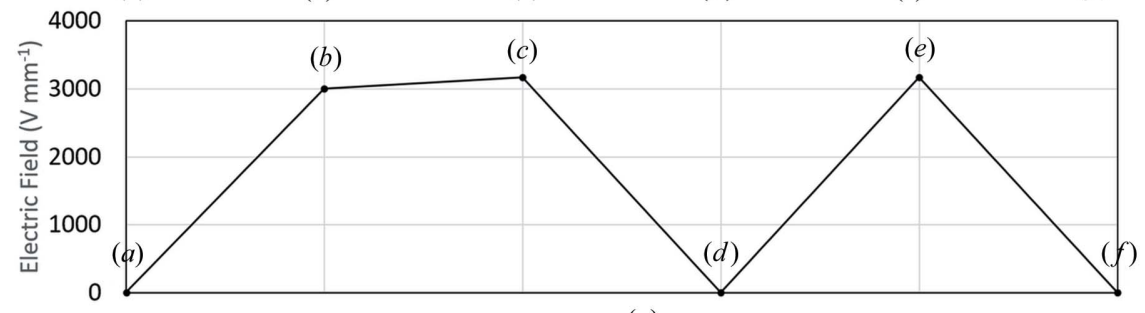

( $g)$

A single-crystal sample of SQABPY-I (cut from a larger plank) mounted in the I19 ELF cell during voltage ramping at room temperature (the sample corresponds to crystal 02 , Table 2 ). The crystal remained yellow up to $1800 \mathrm{~V}(a),(b)$. At $1900 \mathrm{~V}(c)$, a yellow to red-shifted yellow colour change occurs, which is reversible and repeatable with further voltage off/on $(d)-(f)$. $(g)$ Plot of electric field $\left(\mathrm{V} \mathrm{mm} \mathrm{m}^{-1}\right)$ versus crystal appearance. 
Table 2

Crystal size versus voltage at which yellow to red-shifted yellow colour change is induced (switching voltage) and relative critical field.

\begin{tabular}{lllll}
\hline & & $\begin{array}{l}\text { Field gap } \\
(\mathrm{mm})\end{array}$ & $\begin{array}{l}\text { Switching } \\
\text { voltage }(\mathrm{V})\end{array}$ & $\begin{array}{l}\text { Critical field } \\
\left(\mathrm{V} \mathrm{mm}^{-1}\right)\end{array}$ \\
\hline 01 & $1.00(1) \times 0.20(1) \times 0.10(1)$ & 0.2 & 1400 & 7000 \\
02 & $0.60(1) \times 0.60(1) \times 0.20(1)$ & 0.6 & 1900 & 3167 \\
03 & $2.50(1) \times 1.00(1) \times 0.10(1)$ & 1.0 & 2400 & 2400 \\
\hline
\end{tabular}

voltage to $2100 \mathrm{~V}\left(3500 \mathrm{~V} \mathrm{~mm}^{-1}\right)$, where the electric field began to break down. Average colour picker analysis (https:// matkl.github.io/average-color/) from an area of the crystal in images $(a),(c)$ and $(d)$ in Fig. 9 identifies a difference in colour with voltage application (Fig. S4). Initial attempts have been made to quantify the colour change using UV-Vis spectroscopy; however, this setup is still in the early commissioning phases and so no conclusions can yet be drawn from the measurements.

A number of SQABPY-I crystals of different sizes were tested offline for this colour-change behaviour. It was found that the field gap (corresponding to crystal width) affected the point at which the colour change occurred; the larger the crystal, the greater the voltage required to switch the sample (Table 2). The critical field of switching might be expected to remain constant. However, this is not the case here and can be attributed to differences in sample alignment between electrodes or variations in 'actual' voltage being felt by the crystal (there may be slight variations in conductivity between sample cells).

\subsection{In situ diffraction measurements}

To characterize the electric-field-induced colour change in SQABPY-I, in situ single-crystal X-ray diffraction measurements were performed on beamline I19-2, Diamond Light Source, at room temperature on a single crystal [crystal 03 in Table 3; dimensions $2.50(1) \times$ $1.00(1) \times 0.10(1) \mu \mathrm{m}]$ of SQABPY-I mounted in the I19 ELF cell. The SQABPY-I crystal was mounted in the cell in the known field-responsive orientation, i.e. such that the electrodes were attached to the (010) and (010) faces and field application was along the crystallographic $b$-axis direction (see Section 3.2). The diffractometer rotation axis coincided with the crystallographic $a$ axis.

Diffraction data were collected before, during and after the application of electric field. Initially, the crystal was yellow, as expected for SQABPY-I. Upon application of $2400 \mathrm{~V}$, a red shift in the colour was observed, which returned to yellow when the voltage was switched off [Figs. 10(a)-10(c)]. The diffraction data indicated some irreversible change in mosaic spread of

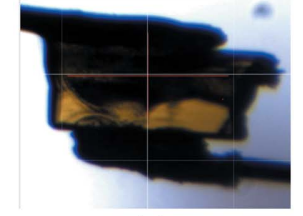

(a)

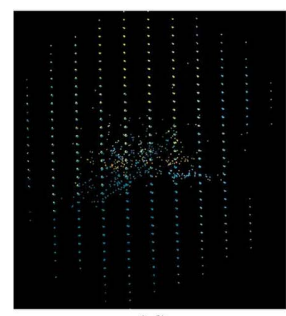

(d)

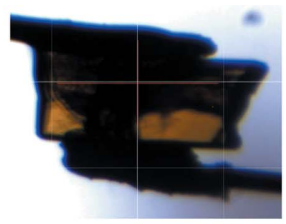

(b)

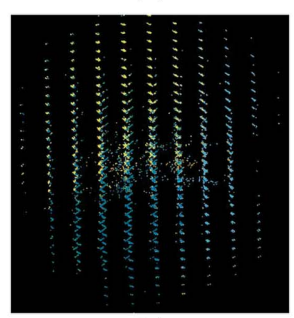

(e)

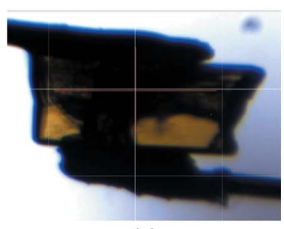

(c)

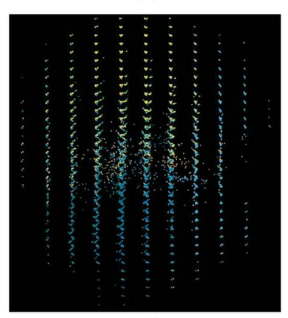

$(f)$
Figure 10

A single-crystal sample of SQABPY-I measured in situ in the I19 ELF cell during voltage ramping and data collection on beamline I19-2, Diamond Light Source. (a) Before-voltage (0 V) yellow form, (b) during-highvoltage $(2400 \mathrm{~V})$ red-shifted yellow form and $(c)$ after-voltage-off $(0 \mathrm{~V})$ yellow form. The reciprocal lattice of diffraction spots (as viewed down the $c$ axis in the DIALS reciprocal lattice viewer) from the data processing spot-finding routine for $(d)$ the before-voltage $(0 \mathrm{~V})$ yellow form, $(e)$ the during-high-voltage $(2400 \mathrm{~V})$ red-shifted yellow form and $(f)$ the after-voltage $(0 \mathrm{~V})$ yellow form.

the crystal by the twinning of diffraction spots [Figs. 10(d)$10(f)]$ and a reduction in the data quality, in particular a significant increase in $\mathrm{R}_{\text {merge }}$ suggesting a worse agreement between equivalent reflections (Table 3), during and after the application of the electric field.

The consistent unit-cell parameters and space group for the before-, during- and post-voltage forms indicate that there are no large structural changes occurring as a function of voltage (Fig. 11 and Table S5). The most significant change occurs in the $c$ axis, which, between before voltage and during voltage on, lengthens by $0.02 \AA$ (a change of $0.07 \%$ ). After the voltage 
Table 3

Crystal data for the before-voltage $(0 \mathrm{~V})$ yellow form, the during-highvoltage $(2400 \mathrm{~V})$ red-shifted yellow form and the after-voltage $(0 \mathrm{~V})$ yellow form.

\begin{tabular}{|c|c|c|c|}
\hline & Before voltage & $\begin{array}{l}\text { During high } \\
\text { voltage }\end{array}$ & After voltage \\
\hline Voltage (V) & 0 & 2400 & 0 \\
\hline Crystal colour & Yellow & $\begin{array}{l}\text { Red-shifted } \\
\text { yellow }\end{array}$ & Yellow \\
\hline Temperature (K) & 298 & 298 & 298 \\
\hline Resolution cut-off $(\AA)$ & 0.75 & 0.75 & 0.75 \\
\hline Crystal system & Monoclinic & Monoclinic & Monoclinic \\
\hline Space group & $P 2_{1} / n$ & $P 2_{1} / n$ & $P 2_{1} / n$ \\
\hline$a(\AA)$ & $3.80060(10)$ & $3.8006(2)$ & $3.7999(3)$ \\
\hline$b(\AA)$ & $11.2125(3)$ & $11.2165(5)$ & $11.2238(6)$ \\
\hline$c(\AA)$ & $27.4464(7)$ & $27.4621(11)$ & $27.4932(14)$ \\
\hline$\alpha\left(^{\circ}\right)$ & 90 & 90 & 90 \\
\hline$\beta\left({ }^{\circ}\right)$ & $92.272(3)$ & $92.271(5)$ & $92.277(6)$ \\
\hline$\gamma\left({ }^{\circ}\right)$ & 90 & 90 & 90 \\
\hline Volume $\left(\AA^{3}\right)$ & $1168.69(5)$ & $1169.77(9)$ & $1171.64(13)$ \\
\hline$Z$ & 4 & 4 & 4 \\
\hline$\rho_{\text {calc }}\left(\mathrm{g} \mathrm{cm}^{-3}\right)$ & 1.536 & 1.534 & 1.532 \\
\hline$\mu\left(\mathrm{mm}^{-1}\right)$ & 0.065 & 0.065 & 0.065 \\
\hline$F(000)$ & 560 & 560 & 560 \\
\hline Crystal size (mm) & $2.5 \times 1.0 \times 0.1$ & $2.5 \times 1.0 \times 0.1$ & $2.5 \times 1.0 \times 0.1$ \\
\hline $\begin{array}{l}\text { Diffraction } \\
\quad \text { wavelength }(\AA)\end{array}$ & 0.534 & 0.534 & 0.534 \\
\hline $\begin{array}{l}2 \theta \text { range for data } \\
\text { collection }\left(^{\circ}\right)\end{array}$ & $2.232-41.586$ & $2.23-41.788$ & $2.228-41.82$ \\
\hline Index ranges & $\begin{array}{l}-5 \leq h \leq 4 \\
-14 \leq k \leq 14 \\
-36 \leq l \leq 36\end{array}$ & $\begin{array}{l}-5 \leq h \leq 4 \\
-14 \leq k \leq 14 \\
-36 \leq l \leq 36\end{array}$ & $\begin{array}{l}-4 \leq h \leq 5 \\
-14 \leq k \leq 14 \\
-36 \leq l \leq 36\end{array}$ \\
\hline Reflections collected & 15341 & 15159 & 15087 \\
\hline Independent & 2791 & 2813 & 2820 \\
\hline reflections & $\begin{array}{l}R_{\text {int }}=0.0649 \\
R_{\text {sigma }}=0.0435\end{array}$ & $\begin{array}{l}R_{\text {int }}=0.0839 \\
R_{\text {sigma }}=0.0847\end{array}$ & $\begin{array}{l}R_{\text {int }}=0.0910 \\
R_{\text {sigma }}=0.0914\end{array}$ \\
\hline $\begin{array}{l}\text { Data/restraints/ } \\
\text { parameters }\end{array}$ & $2791 / 0 / 222$ & $2813 / 2 / 226$ & $2820 / 0 / 222$ \\
\hline Goodness-of-fit on $F^{2}$ & 1.129 & 0.828 & 0.822 \\
\hline $\begin{array}{l}\text { Final } R \text { indices } \\
\qquad[I \geq 2 \sigma(I)]\end{array}$ & $\begin{array}{l}R_{1}=0.0418 \\
w R_{2}=0.1096\end{array}$ & $\begin{array}{l}R_{1}=0.0495 \\
w R_{2}=0.1037\end{array}$ & $\begin{array}{l}R_{1}=0.0493 \\
w R_{2}=0.1025\end{array}$ \\
\hline $\begin{array}{l}\text { Final } R \text { indices } \\
\quad \text { (all data) }\end{array}$ & $\begin{array}{l}R_{1}=0.0526 \\
w R_{2}=0.1203\end{array}$ & $\begin{array}{l}R_{1}=0.0770 \\
w R_{2}=0.1136\end{array}$ & $\begin{array}{l}R_{1}=0.0758 \\
w R_{2}=0.1124\end{array}$ \\
\hline $\begin{array}{l}\text { Largest peak/hole } \\
\text { difference }\left(\mathrm{e} \AA^{-3}\right)\end{array}$ & $0.335 /-0.209$ & $0.27 /-0.22$ & $0.306 /-0.223$ \\
\hline
\end{tabular}

is turned off, the unit-cell parameters do not relax to their start values. This may be a factor of the irreversible twinning of the crystal post voltage application. However, it could also be caused by remnant voltage effects felt by the crystal as the 'after-voltage' data collection was performed immediately after turning the voltage off with a maximum delay of minutes, the time taken for the diffractometer to move to the data collection start position. A longer delay may have allowed the crystal to relax to its initial state (Lau et al., 2015), though this can be between hours and days and was beyond the allowed time of the experiment.

The $c$ axis coincides most with the direction of the hydrogen-bonded chain (Fig. 7). This prompted a closer look at the atomic coordinates of SQABPY-1, to examine if any structural changes had occurred and if they bore any similarity to those observed in the thermal phase transition between SQABPY-I and SQABPY-II.

The crystal structures for the before, during and after forms show that there is no shift in the non-H-atom positions as a function of voltage (Fig. S5). There is, however, residual electron density located in the bonding region of the unprotonated 4,4'-bipyridinium nitrogen atom (Fig. 12) in the during- and after-voltage structures, apparent when the hydrogen squarate proton is left un-modelled. This residual electron density is evident in both Fourier difference maps and is indicated by a $Q$ peak following SHELXL refinement in Olex2-1.3. This peak of residual electron density indicates a potential disorder of this proton across the $\mathrm{O}-\mathrm{H} \cdots \mathrm{N}$

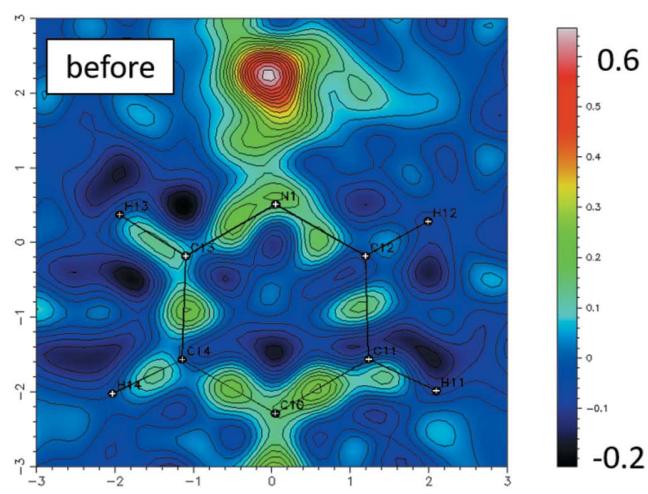

(a)

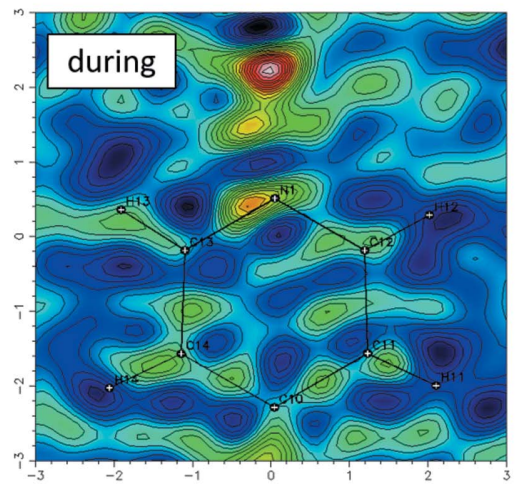

(c)

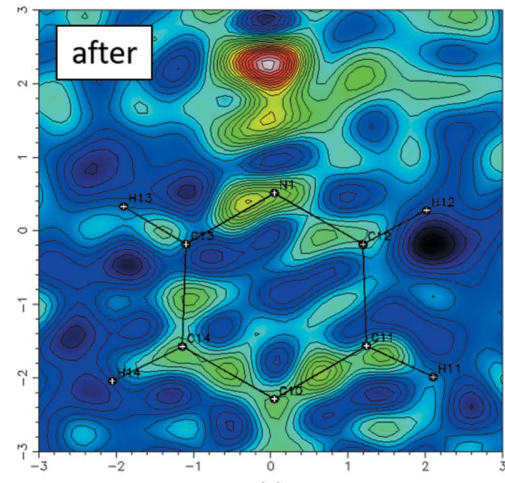

(e)

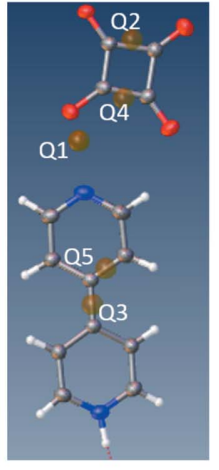

(b)

\section{Figure 12}

Residual electron density maps generated in the plane of the pyridinium $\mathrm{C}-\mathrm{N}-\mathrm{C}$ atoms and in the region of the $\mathrm{O}-\mathrm{H} \cdots \mathrm{N}$ hydrogen bond formed between the hydrogen squarate and the un-protonated 4,4'bipyridinium nitrogen atom for $(a),(b)$ the before-voltage $(0 \mathrm{~V})$ yellow form, $(c),(d)$ the during-high-voltage $(2400 \mathrm{~V})$ red-shifted yellow form and $(e),(f)$ the after-voltage-off $(0 \mathrm{~V})$ yellow form. Residuals are indicated as maxima (red regions) in the Fourier difference electron density maps $(a),(c),(e)$ or as $Q$ peaks (brown spheres) visualized in Olex2-1.3 $(b),(d),(f)$. The $\mathrm{O}-\mathrm{H} \cdots \mathrm{N} \mathrm{H}$ atom is omitted from the model. 
hydrogen bond to the un-protonated 4,4'-bipyridinium nitrogen atom. The second hydrogen atom peak has the greatest intensity for the during-high-voltage form, suggesting that it is caused by the application of the electric field. The fact that it remains to an extent in the subsequent after-voltage-off form indicates that the crystal has not yet fully 'relaxed' after the voltage being turned off (as seen in the unit-cell parameters).

To check the likelihood of electric-field-induced proton disorder, a proton disorder model was refined for all three forms (see Table $\mathrm{S} 4$ for the $\mathrm{H}$-atom model used). A stable disorder model was only achieved for the during-high-voltage form; the second hydrogen atom occupied a chemically sensible position, in the plane of the bipyridine ring. The occupancies of the major (on the acid) and minor (on the bipyridine) disordered proton sites refined to a 80:20 split, indicating a low but present occupation of the second $\mathrm{H}$-atom site in the $\mathrm{O}-\mathrm{H} \cdots \mathrm{N}$ hydrogen bond as a result of the applied electric field. In contrast, when applying the same disorder model to the before- and after-voltage forms, the $\mathrm{H}$ atom deviates from being in a chemically sensible position, lifting up and out of the plane of the bipyridine ring it is bonded to. An unstable model suggests that proton disorder is most likely absent in the before- and after-high-voltage forms.

Indexing of the crystal habit shows that the electric field was applied parallel to the crystallographic $b$ axis, perpendicular to the $(010)$ and $(0 \overline{10})$ faces. This axis is almost perpendicular to the hydrogen-bonding direction (Fig. 7) and may explain why only a small extent of proton disorder is observed following electric field application. Future measurements targeting crystal alignment such that the electrodes are attached to the $(001)$ and $(00 \overline{1})$ faces and the electric field is applied parallel to the crystallographic $c$ axis could result in a greater disorder of the protons, possibly to the extent that the red SQABPY-II form is accessible. This will be the focus of follow-up studies on this system.

The early evidence presented here suggests that a small extent of proton disorder may be responsible for the colour change observed on application of an electric field to SQABPY-I. As determined by the in situ diffraction measurements; the field leads to a proton hopping of the

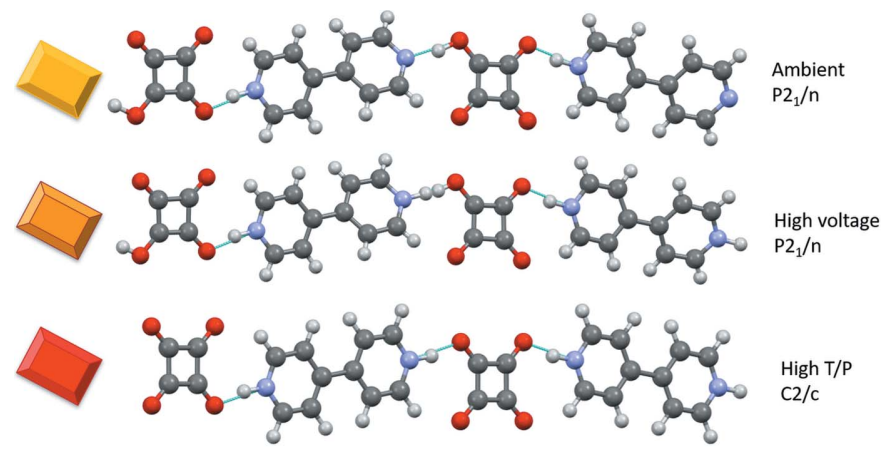

Figure 13

Summary of structures of squarate 4,4'-bipyridinium salts including a yellow $P 2_{1} / n$ form (CSD refcode HAZFAP01; Martins et al., 2009) at ambient conditions, a high-voltage red-shifted yellow $P 2_{1} / n$ form and a high-temperature/pressure red $C 2 / c$ form (CSD refcode HAZFAP07; Martins et al., 2009). second hydrogen squarate proton towards the monoprotonated 4,4'-bipyridinium molecule. In the extreme, full hopping would result in a structure containing both the squarate anion and the doubly protonated $4,4^{\prime}$-bipyridinium molecule, similar to the high-temperature red form, SQABPYII. It is therefore reasonable that a partially proton transferred state could lead to the intermediate red-shifted yellow form (Fig. 13) which is achieved here at a field strength of $2.4 \mathrm{kV} \mathrm{mm}^{-1}$, although it should be noted that the critical field needed to induce a visible colour change in other crystals could be higher.

\section{Conclusions}

In this work we have presented for the first time the I19 ELF cell for use in single-crystal synchrotron X-ray diffraction measurements. We have shown how it allows the user to elucidate electric-field-induced structural responses in situ during a diffraction experiment. This is a significant step in electric field studies where few experimental setups exist that allow in situ structure determination from single crystals.

Using the I19 ELF cell, we have identified an interesting electric-field-sensitive material, SQABPY-I, found to change colour on application of an electric field. In these preliminary results, by performing in situ diffraction measurements, the voltage-induced colour change can be linked to the extent of proton disorder within the system. Whilst proton transfer has previously been linked to colour change in other single-crystal systems (Jones et al., 2014; Yano et al., 2019), cases of proton hopping as a function of electric field in organic molecular systems remain rare (Varela et al., 2000; Horiuchi et al., 2010). Even more so are experimental studies of proton transfer performed in situ during a single-crystal diffraction experiment. We continue to work on the development of the cell, for its optimization towards smaller samples and time-resolved measurements, in order to cater better to the varied I19-2 user community.

\section{Acknowledgements}

We acknowledge Diamond Light Source for access to beamline I19-2 under proposals cm19670-5 and $\mathrm{cm} 22964-3$. There are no conflicts of interest to report.

\section{References}

Abronin, I. A., Koval'chuk, I. A. \& Sakun, V. P. (2016). Russ. J. Phys. Chem. B, 10, 357-359.

Amanuma, K., Kobayashi, S., Tatsumi, T., Maejima, Y., Hada, H., Yamada, J., Miwa, T., Koike, H., Toyoshima, H. \& Kunio, T. (2000). Jpn. J. Appl. Phys. 39, 2098-2101.

Bai, Y., Zhou, Z.-J., Wang, J.-J., Li, Y., Wu, D., Chen, W., Li, Z.-R. \& Sun, C.-C. (2013). J. Mol. Model. 19, 3983-3991.

Bouregba, R., Vilquin, B., Le Rhun, G., Poullain, G. \& Domenges, B. (2003). Rev. Sci. Instrum. 74, 4429-4435.

Choe, H., Heidbrink, S., Ziolkowski, M., Pietsch, U., Dyadkin, V., Gorfman, S. \& Chernyshov, D. (2017). J. Appl. Cryst. 50, 975-977. Dawber, M., Rabe, K. M. \& Scott, J. F. (2005). Rev. Mod. Phys. 77, 1083-1130. 
Dolomanov, O. V., Bourhis, L. J., Gildea, R. J., Howard, J. A. K. \& Puschmann, H. (2009). J. Appl. Cryst. 42, 339-341.

Dos Santos, L. H. R., Rodrigues, B. L., Idemori, Y. M. \& Fernandes, N. G. (2012). J. Mol. Struct. 1014, 102-109.

Esteves, G., Fancher, C. M. \& Jones, J. L. (2015). J. Mater. Res. 30, 340-356.

Giacovazzo, C., Monaco, H. L., Artioli, G., Viterbo, D., Milanesio, M., Gilli, G., Gilli, P., Zanotti, G., Ferraris, G. \& Catti, M. (2011). Fundamentals of Crystallography, 3 ed. Oxford University Press.

Gibbons, E. P., Heron, M. T. \& Rees, N. P. (2012). 13th International Conference on Accelerator and Large Experimental Physics Control Systems (ICALEPCS 2011), 10-14 October 2011, Grenoble, France.

Gorfman, S., Schmidt, O., Tsirelson, V., Ziolkowski, M. \& Pietsch, U. (2013). Z. Anorg. Allg. Chem. 639, 1953-1962.

Grigoriev, S. V., Maleyev, S. V., Okorokov, A. I., Chetverikov, Y. O., Böni, P., Georgii, R., Lamago, D., Eckerlebe, H. \& Pranzas, K. (2006). Phys. Rev. B, 74, 214414.

Haertling, G. H. (1999). J. Am. Ceram. Soc. 82, 797-818.

Hinterstein, M., Hoelzel, M., Rouquette, J., Haines, J., Glaum, J., Kungl, H. \& Hoffman, M. (2015). Acta Mater. 94, 319-327.

Hinterstein, M., Lee, K. Y., Esslinger, S., Glaum, J., Studer, A. J., Hoffman, M. \& Hoffmann, M. J. (2019). Phys. Rev. B, 99, 174107.

Hinterstein, M., Rouquette, J., Haines, J., Papet, P., Knapp, M., Glaum, J. \& Fuess, H. (2011). Phys. Rev. Lett. 107, 077602.

Horiuchi, S. \& Ishibashi, S. (2020). J. Phys. Soc. Jpn, 89, 051009.

Horiuchi, S., Ishibashi, S., Haruki, R., Kumai, R., Inada, S. \& Aoyagi, S. (2020). Chem. Sci. 11, 6183-6192.

Horiuchi, S., Ishii, F., Kumai, R., Okimoto, Y., Tachibana, H., Nagaosa, N. \& Tokura, Y. (2005). Nat. Mater. 4, 163-166.

Horiuchi, S., Kagawa, F., Hatahara, K., Kobayashi, K., Kumai, R., Murakami, Y. \& Tokura, Y. (2012). Nat. Commun. 3, 1308.

Horiuchi, S., Kobayashi, K., Kumai, R. \& Ishibashi, S. (2017). Nat. Commun. 8, 14426.

Horiuchi, S., Kumai, R. \& Ishibashi, S. (2018). Chem. Sci. 9, 425-432.

Horiuchi, S., Kumai, R., Tokunaga, Y. \& Tokura, Y. (2008). J. Am. Chem. Soc. 130, 13382-13391.

Horiuchi, S., Kumai, R. \& Tokura, Y. (2009). J. Mater. Chem. 19, 4421-4434.

Horiuchi, S., Kumai, R. \& Tokura, Y. (2013). J. Am. Chem. Soc. 135, 4492-4500.

Horiuchi, S., Tokunaga, Y., Giovannetti, G., Picozzi, S., Itoh, H., Shimano, R., Kumai, R. \& Tokura, Y. (2010). Nature, 463, 789-792.

Horiuchi, S. \& Tokura, Y. (2008). Nat. Mater. 7, 357-366.

Horiuchi, S., Tsutsumi, J., Kobayashi, K., Kumai, R. \& Ishibashi, S. (2018). J. Mater. Chem. C, 6, 4714-4719.

Jones, C. L., Wilson, C. C. \& Thomas, L. H. (2014). CrystEngComm, 16, 5849-5858.

Kobayashi, K., Horiuchi, S., Ishibashi, S., Murakami, Y. \& Kumai, R. (2018). J. Am. Chem. Soc. 140, 3842-3845.

Lau, K., Barlow, A., Moxey, G. J., Li, Q., Liu, Y., Humphrey, M. G., Cifuentes, M. P., Frankcombe, T. J. \& Stranger, R. (2015). Phys. Chem. Chem. Phys. 17, 10781-10785.

Lengyel, J., Wang, X., Choi, E. S., Besara, T., Schönemann, R., Ramakrishna, S. K., Holleman, J., Blockmon, A. L., Hughey, K. D., Liu, T., Hudis, J., Beery, D., Balicas, L., McGill, S. A., Hanson, K., Musfeldt, J. L., Siegrist, T., Dalal, N. S. \& Shatruk, M. (2019). J. Am. Chem. Soc. 141, 16279-16287.

Li, Z., Huang, H., Zhang, T., Xu, J., Zhang, J. \& Yang, L. (2015). J. Phys. Chem. C, 119, 8431-8437.

Macrae, C. F., Edgington, P. R., McCabe, P., Pidcock, E., Shields, G. P., Taylor, R., Towler, M. \& van de Streek, J. (2006). J. Appl. Cryst. 39, 453-457.

Macrae, C. F., Sovago, I., Cottrell, S. J., Galek, P. T. A., McCabe, P., Pidcock, E., Platings, M., Shields, G. P., Stevens, J. S., Towler, M. \& Wood, P. A. (2020). J. Appl. Cryst. 53, 226-235.

Marchenkov, N. V., Kulikov, A. G., Petrenko, A. A., Pisarevsky, Y. V. \& Blagov, A. E. (2018). Rev. Sci. Instrum. 89, 095105.
Martins, D. M. S., Middlemiss, D. S., Pulham, C. R., Wilson, C. C., Weller, M. T., Henry, P. F., Shankland, N., Shankland, K., Marshall, W. G., Ibberson, R. M., Knight, K., Moggach, S., Brunelli, M. \& Morrison, C. A. (2009). J. Am. Chem. Soc. 131, 3884-3893.

Miyamoto, T., Hata, D., Morimoto, T., Yamakawa, H., Kida, N., Terashige, T., Iwano, K., Kishida, H., Horiuchi, S. \& Okamoto, H. (2018). Sci. Rep. 8, 15014.

Mykhaylyk, V. B., Wagner, A. \& Kraus, H. (2017). J. Synchrotron Rad. 24, 636-645.

Nowell, H., Barnett, S. A., Christensen, K. E., Teat, S. J. \& Allan, D. R. (2012). J. Synchrotron Rad. 19, 435-441.

Owczarek, M., Hujsak, K. A., Ferris, D. P., Prokofjevs, A., Majerz, I., Szklarz, P., Zhang, H., Sarjeant, A. A., Stern, C. L., Jakubas, R., Hong, S., Dravid, V. P. \& Stoddart, J. F. (2016). Nat. Commun. 7, 13108.

Reetz, M. T., Höger, S. \& Harms, K. (1994). Angew. Chem. Int. Ed. Engl. 33, 181-183.

Reeuwijk, S. J. van, Puig-Molina, A. \& Graafsma, H. (2000). Phys. Rev. B, 62, 6192-6197.

Rode, M. F., Jankowska, J. \& Sobolewski, A. L. (2016). J. Chem. Phys. 144, 134303.

Rodzevich, A. P., Gazenaur, E. G., Kuzmina, L. V., Krasheninin, V. I. \& Gazenaur, N. V. (2017). J. Phys. Conf. Ser. 830, 012131.

Saunders, L. K., Nowell, H., Hatcher, L. E., Shepherd, H. J., Teat, S. J., Allan, D. R., Raithby, P. R. \& Wilson, C. C. (2019). CrystEngComm, 21, 5249-5260.

Sawyer, C. B. \& Tower, C. H. (1930). Phys. Rev. 35, 269-273.

Schmalzried, H. \& Smolin, S. (1998). Ber. Bunsen Gesell. Phys. Chem. 102, 1740-1746.

Sheldrick, G. M. (2015a). Acta Cryst. A71, 3-8.

Sheldrick, G. M. (2015b). Acta Cryst. C71, 3-8.

Sinclair, J. (2007). EDM: Extensible Display Manager, https://www. slac.stanford.edu/grp/ssrl/spear/epics/extensions/edm/edm.html.

Stroppa, A., Di Sante, D., Horiuchi, S., Tokura, Y., Vanderbilt, D. \& Picozzi, S. (2011). Phys. Rev. B, 84, 014101.

Tazaki, R., Fu, D., Itoh, M., Daimon, M. \& Koshihara, S. (2009). J. Phys. Condens. Matter, 21, 215903.

Tolédano, P. \& Guennou, M. (2016). Phys. Rev. B, 94, 014107.

Usher, T.-M., Levin, I., Daniels, J. E. \& Jones, J. L. (2015). Sci. Rep. 5, 14678.

Varela, A. T., Sasaki, J. M., Guedes, I., Freire, P. T. C., Ayala, A. P., Filho, J. M., Melo, F. E. A. \& Chaves, A. S. (2000). arXiv:condMater/0001364.

Vergentev, T., Bronwald, I., Chernyshov, D., Gorfman, S., Ryding, S. H. M., Thompson, P. \& Cernik, R. J. (2016). J. Appl. Cryst. 49, 15011507.

Vergentev, T. Y., Dyadkin, V. \& Chernyshov, D. Y. (2015). J. Synch. Investig. 9, 436-441.

Werling, K. A., Hutchison, G. R. \& Lambrecht, D. S. (2013). J. Phys. Chem. Lett. 4, 1365-1370.

Wersing, W., Heywang, W., Beige, H. \& Thomann, H. (2008). Piezoelectricity: Evolution and Future of a Technology, edited by W. Heywang, K. Lubitz \& W. Wersing, pp. 37-87. Berlin, Heidelberg: Springer.

Wilson, A. J. C. (1942). Nature, 150, 152.

Winter, G. (2010). J. Appl. Cryst. 43, 186-190.

Winter, G., Waterman, D. G., Parkhurst, J. M., Brewster, A. S., Gildea, R. J., Gerstel, M., Fuentes-Montero, L., Vollmar, M., MichelsClark, T., Young, I. D., Sauter, N. K. \& Evans, G. (2018). Acta Cryst. D74, 85-97.

Yano, Y., Ono, T., Hatanaka, S., Gryko, D. T. \& Hisaeda, Y. (2019). J. Mater. Chem. C, 7, 8847-8854.

Yao, Z.-S., Yamamoto, K., Cai, H.-L., Takahashi, K. \& Sato, O. (2016). J. Am. Chem. Soc. 138, 12005-12008.

Zhang, N., Gorfman, S., Choe, H., Vergentev, T., Dyadkin, V., Yokota, H., Chernyshov, D., Wang, B., Glazer, A. M., Ren, W. \& Ye, Z.-G. (2018). J. Appl. Cryst. 51, 1396-1403.

Zhang, W. \& Xiong, R.-G. (2012). Chem. Rev. 112, 1163-1195. 